\title{
DESIGN AND OPTIMIZATION OF A SOYBEAN SUPPLY CHAIN NETWORK UNDER UNCERTAINTY
}

by

Sogand Shekarian

B.Sc. in Industrial Engineering, Azad University, Tehran, Iran, 2009

M.Sc. in Engineering Management, San Jose State University, San Jose, USA, 2017

\author{
A major research project \\ presented to Ryerson University \\ in partial fulfillment of the \\ requirements for the degree of \\ Master of Engineering \\ in the program of
}

Mechanical and Industrial Engineering

Toronto, Ontario, Canada, 2019

(C)Sogand Shekarian, 2019 


\section{Author's Declaration}

\section{AUTHOR'S DECLARATION}

I hereby declare that I am the sole author of this MRP. This is a true copy of the MRP, including any required final revisions.

I authorize Ryerson University to lend this MRP to other institutions or individuals for the purpose of scholarly research.

I further authorize Ryerson University to reproduce this MRP by photocopying or by other means, in total or in part, at the request of other institutions or individuals for the purpose of scholarly research.

I understand that my MRP may be made electronically available to the public. 


\title{
Design and optimization of a soybean supply chain network under uncertainty
}

\author{
Master of Engineering, 2019 \\ Sogand Shekarian \\ Industrial Engineering \\ Ryerson University
}

\begin{abstract}
Demands of foods have been increased in recent years for human and animal nutrition. Food supply chain management has been required to administer series of products and services in efficient ways for agriculture and food production to achieve customer satisfaction at the lowest cost. Agricultural systems have been changed during recent years, and have caused improvements in consumption and production patterns. However, there is not much research on supply chains of seeds (e.g., soybean) which have been produced in Canada. In this research, we propose a mixedinteger linear optimization formulation for a soybean supply chain network. The profit is maximized in the objective function. The mathematical formulation consists of multiple products, growers, potential farm company facilities, potential locations of distributers, and customers. Then, the mathematical model is extended by possibilistic approach to include uncertain parameters. In addition, the results are discussed and analyzed for the soybean supply chain network.
\end{abstract}




\section{Acknowledgments}

I would like to express my very great appreciation to my supervisor, Dr. Saman Hassanzadeh Amin whose guidance, expertise and encouragement were greatly helpful to me throughout my project. He has definitely contributed to the success of this work very much. 


\section{Table of Contents}

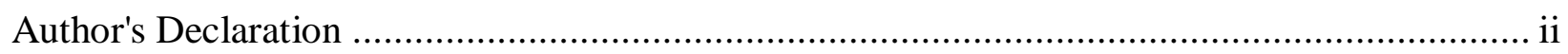

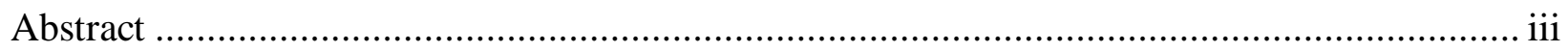

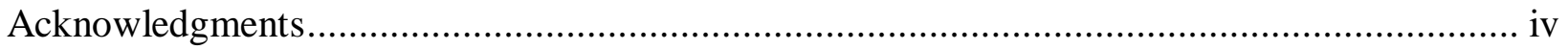

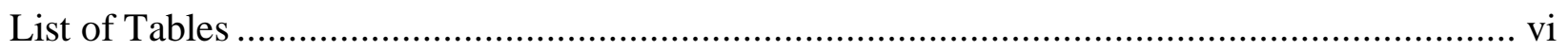

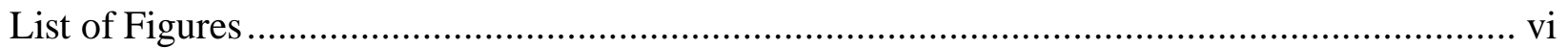

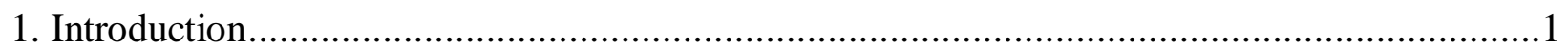

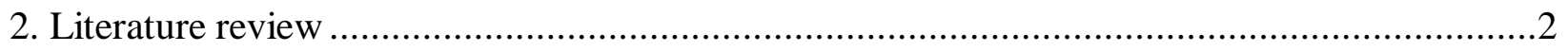

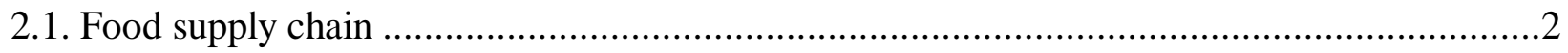

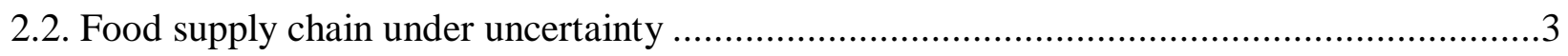

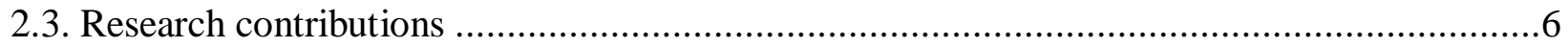

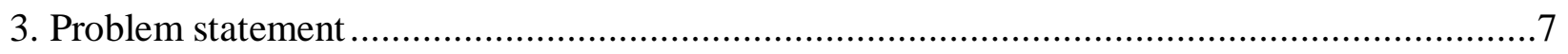

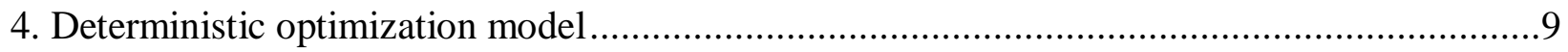

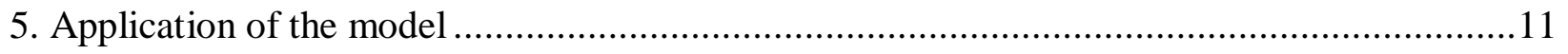

6. Extension to multi-period possibilistic model .................................................... 14

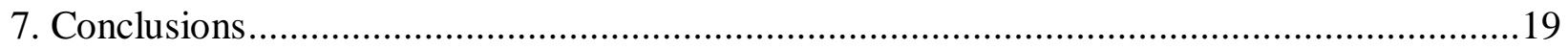

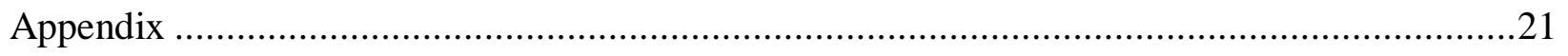

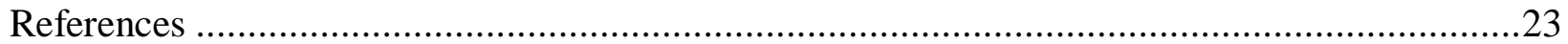




\section{List of Tables}

Table 1: Review of some related papers utilized in food supply chain networks .......................5

Table 2: The optimal solutions based on different satisfaction levels ..................................18

Table 3: The values of some parameters in the deterministic model ...................................21

Table 4: Purchasing cost related to product $\mathrm{j}$ from grower s.............................................21

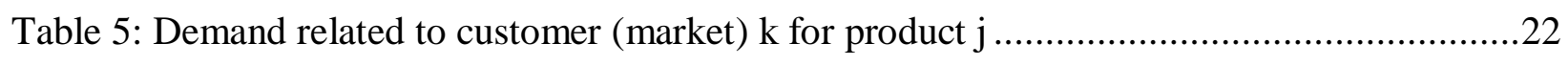

\section{List of Figures}

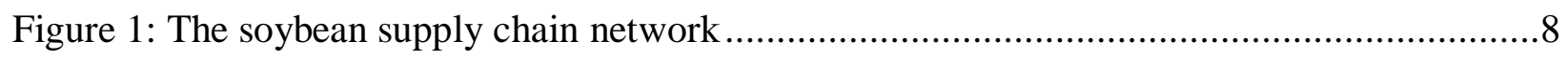

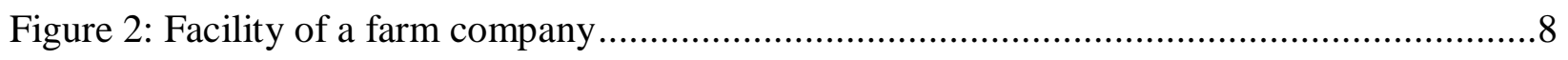

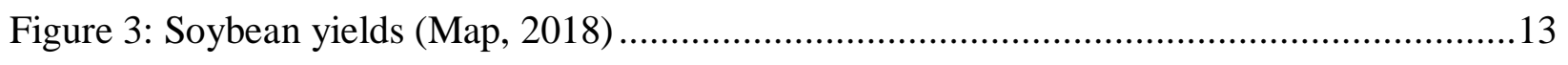

Figure 4: The optimal soybean supply chain network ............................................. 14

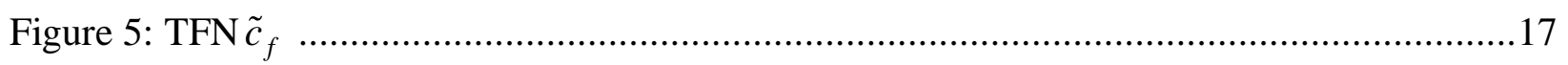




\section{Introduction}

Growing population in the world is a reason to produce more products such as food items, and find strategies to reduce waste. Hence, the food supply chain needs to be restructured to handle the demands effectively. Supply chain management techniques are effective tools for researchers and manufacturers to acquire and analyze the results (De Laporte et al., 2016; Rahimi et al., 2018). Production processes of agricultural products and foods have been altered in recent years causing changes in production and distribution systems (Govindan, 2018).

Seeds play a pivotal role in human and animal daily food. Among different types of seeds, soybean is an important one that has received considerable attention (Garrett et al., 2013; Zortea et al., 2018; Gollnow et al., 2018). Soybean was not very important crop in North America before World War II. They were grown in Ontario in 1893, and were produced in the early 1930's commercially. In today's competitive economy, parameters such as demand and cost are important factors and vary in different situations, thus these factors cause some risks (Mohammed and Wang, 2017a). Some of these risks are related to uncertainty in diverse factors that should be considered in design and configuration of food supply chain networks. In this study, a mixed-integer linear optimization model for a food supply chain network is developed considering different sources of uncertainty.

In Section 2, the review of literature is provided. Section 3 is devoted to the problem statement. A deterministic formulation is proposed in Section 4. Then, the application of the formulation is demonstrated in Section 5. In Section 6, the mathematical formulation under uncertainty is developed. Finally, conclusions are discussed in Section 7. 


\section{Literature review}

In recent years, the research publications in supply chain field have been increased significantly. In this section, some academic papers related to food supply chain and food supply chain under uncertainty are discussed. In addition, the contributions of our research are mentioned.

\subsection{Food supply chain}

There are some studies about food supply chain management. Soysal et al. (2014) developed a mixed-integer optimization model and a multi-objective linear programming formulation for a problem in beef industry. The objectives of the models were defined to minimize two important factors including cost and amount of greenhouse gas emissions in the transportation system. Mishra et al. (2016) provided a nonlinear programming model to optimize storage temperature of leafy greens in the supply chain. The objective function was minimization of refrigeration cost.

Mohammed and Wang (2017b) provided a model to minimize the total cost of transportation, the delivery time, and the number of vehicles for a food supply chain network. LP-metrics technique, $\varepsilon$-constraint technique, and weighted Tchebycheff solution approach were utilized in their paper. They concluded that $\varepsilon$-constraint method obtained better solutions than the other methods. Mohammed and Wang (2017a) published a paper about the application of radiofrequency identification (RFID) in a food supply chain network focusing on meat products. A costeffective trade-off decision from an optimization model with three objectives were provided. The objectives were customer satisfaction, product quality, and total implementation cost. Govindan (2018) described sustainability of food supply chains related to consumption and production. He mentioned that food industry stakeholders were coordinated. He identified trends, drivers, and obstacles related to stakeholders to gain sustainable food supply chain. Mogale et al. (2018) 
presented an integrated multi-objective and dynamic optimization formulation for grain silo to support government decisions. The model contains two objectives (minimization of lead time and cost). Asche et al. (2018) investigated the supply chains of salmon and chicken and compared them. They provided useful information about the production processes of them.

Some authors have investigated soybean production, and the effects of soybean on human landscapes. However, a few academic papers have focused on soybean supply chain management. Garrett et al. (2013) employed a model to recognize biophysical factors, economic conditions, and their importance in soybean yields. They considered soy production profits, supply chain settings, and their relationship. They applied Thünen's spatial model and bioeconomic yield to determine the total yield. Reis and Leal (2015) applied a mathematical model that consists of continuous and non-negative variables for a soybean supply chain network in Brazil. The model was purposed to be a decision-making tool for the soybean supply chain. The model was a source of information for shippers and investors.

\subsection{Food supply chain under uncertainty}

Supply chain management under uncertainty can cope the complexity of several issues that happen in many industries (Cui et al., 2017; Ghelichi et al., 2018; Wu et al., 2018). As a result, some researchers have developed some techniques to handle sources of uncertainty in operations management problems such as food logistics problems (Simangunsong et al., 2012). Baghalian et al. (2013) provided a stochastic mathematical model considering multiple products, multiple facilities, distributors, and retailers under uncertainty in the agri-food industry. The model which incorporated the cut-set concept and the robust optimization method is a mixed-integer nonlinear programming one. 
Hasuike et al. (2014) proposed an optimization model for a food supply chain that maximizes the total profit in multiple periods. The model was formulated by stochastic programming technique and focused on accommodating surplus foods among stores in a regional area. Crop productions and customers' demands were uncertain factors. Soysal et al. (2015) studied a multiple period inventory routing problem (IRP) which consisted of service level limitation and fuel consumption based on inexact demands. Amorim et al. (2016) discussed a novel two-stage stochastic mixed-integer mathematical model in a food supply chain network to select the best supplier(s). The purpose of their study was to maximize profit and minimize the risk of low customer service. They also discussed food supply chain management under uncertainty at downstream and upstream situations. Then, they developed a solution approach. Rijpkema et al. (2016) proposed a programming model for a meat processing company which was under uncertainty. The model focused on the product quality level from the farmer delivery data. Sel et al. (2017) developed a stochastic programming model for the total waste, total cost production and distribution in a food supply chain under demand uncertainty.

A summary of the relevant papers in food supply chain network with main attributes, and the status of our paper in comparison with them have been written in Table 1. 
Table 1: Review of some related papers utilized in food supply chain networks

\begin{tabular}{|c|c|c|c|c|c|c|}
\hline Authors & Technique & $\begin{array}{l}\text { Type of } \\
\text { food }\end{array}$ & $\begin{array}{l}\text { Real } \\
\text { locations }\end{array}$ & Uncertainty & $\begin{array}{l}\text { Multiple } \\
\text { distributors }\end{array}$ & $\begin{array}{l}\text { Multiple } \\
\text { products }\end{array}$ \\
\hline $\begin{array}{l}\text { Gupta and Maranas } \\
\text { (2003) }\end{array}$ & MILP & & & $\checkmark$ & & $\checkmark$ \\
\hline Peidro et al. (2009) & FMILP & & & $\checkmark$ & & \\
\hline Mirzapour et al. (2011) & MOMILP & & $\begin{array}{l}\text { Industrial } \\
\text { case study }\end{array}$ & & & $\checkmark$ \\
\hline Rong et al. (2011) & $\begin{array}{l}\text { MILP } \\
\text { Optimization }\end{array}$ & & Case study & & & $\checkmark$ \\
\hline Zheng and Cao (2011) & $\begin{array}{l}\text { scheme of supply } \\
\text { chain }\end{array}$ & & $\begin{array}{l}\text { Real } \\
\text { company }\end{array}$ & & & \\
\hline Ahumada et al. (2012) & $\begin{array}{l}\text { Stochastic } \\
\text { programming }\end{array}$ & & Mexico & $\checkmark$ & & \\
\hline Garrett et al. (2013) & $\begin{array}{l}\text { Thünen's spatial } \\
\text { market model }\end{array}$ & Soybean & Brazil & & & \\
\hline Soysal et al. (2014) & MILP, MOLP & Beef & Brazil & & & \\
\hline Reis and Leal (2015) & $\mathrm{LP}$ & Soybean & & & & \\
\hline Banasik et al. (2017) & MOMILP & & & & & $\checkmark$ \\
\hline $\begin{array}{l}\text { Mohammed and Wang } \\
\text { (2017c) }\end{array}$ & FMOPM & Meat & & $\checkmark$ & & \\
\hline Aras and Bilge (2018) & MILP & & & & & \\
\hline Our paper & MILP & Soybean & $\checkmark$ & $\checkmark$ & $\checkmark$ & $\checkmark$ \\
\hline
\end{tabular}




\subsection{Research contributions}

In this study, a mixed-integer linear optimization formulation (deterministic one) is introduced for a soybean supply chain. Then, the optimization model is extended to take into account uncertainty in some factors. To our knowledge, this investigation is the first one that takes into account network optimization of a soybean supply chain under uncertainty in Ontario (the most populous province of Canada). The significant research features of this paper are as follows:

- A unique optimization model is developed for a food (soybean) logistics network taking into consideration several growers, farm facilities, distributors, and customers. In addition, the model is designed for various products. The goal of this mathematical model is profit maximization.

- The application of the developed formulation is demonstrated using real locations in Ontario. To this aim, Google Maps are utilized.

- The distances among the locations of the facilities in the problem are obtained utilizing Google Maps.

- Possibilistic approach is utilized to extend the deterministic model. This new model can handle the effects of uncertainty in different parameters of the soybean supply chain. It is noticeable that uncertainty has been ignored in most of the papers in the food supply chain literature. 


\section{Problem statement}

Soybean is a cheap product that contains significant amount of protein. It is an important seed for providing oil and some products (Riaz, 2006). Soybean was first introduced to Ontario as a forage crop for livestock nutrition. Growing soybean has over 70 years' history in Ontario. Soybean has rank four among Canada's principal crops. Ontario had 7,716,600 million tonnes soybean production that seeded areas were 7,282,000 million acres in 2017 (Soybean, 2018). Time of harvest plays a prominent role, and it is the biggest consideration in the soybean quality and yield.

Several soybean companies are located in Southern and Southwestern of Ontario. The soybean supply chain in this study contains some elements. Fig. 1 illustrates the supply chain network of soybean. The network includes growers, farm company facilities, distributors, and customers (markets). Fig. 2 illustrates a facility of a soybean farm company in Ontario. The company purchases seeds from growers. The relationship of farm company with growers is yearlong and consists of contracting, monitoring, field visits, inspections of bins, and gathering the finished products. Some processes are applied inside the farm company. The soybean process inside the company is a wet application and once on the seed, it becomes very tacky. This product requires a minimum of 12 hours drying time so that it can fractionate and move through a bulk seed system. HiCoat is a popular technology for pre-inoculation of soybean seeds which has been used to protect soybean seeds without extra drying after application. It consists of two formulations which are peat-base formulation and liquid formation (HiCoat, 2018). After HiCoat process, the products are sent to the packaging room in the farm company. Then, they are delivered to distributors. In the next stage, the products are sent to customers (demand markets). 
This company would like to find answers for different questions including: Which grower(s) should be selected? Which facility or facilities should be chosen? Which distributor(s) should be selected? How much soybean is there in every section of the soybean supply chain network?

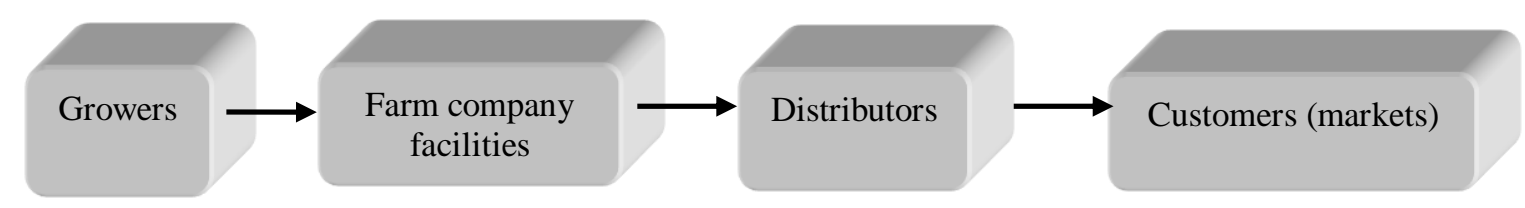

Figure 1: The soybean supply chain network

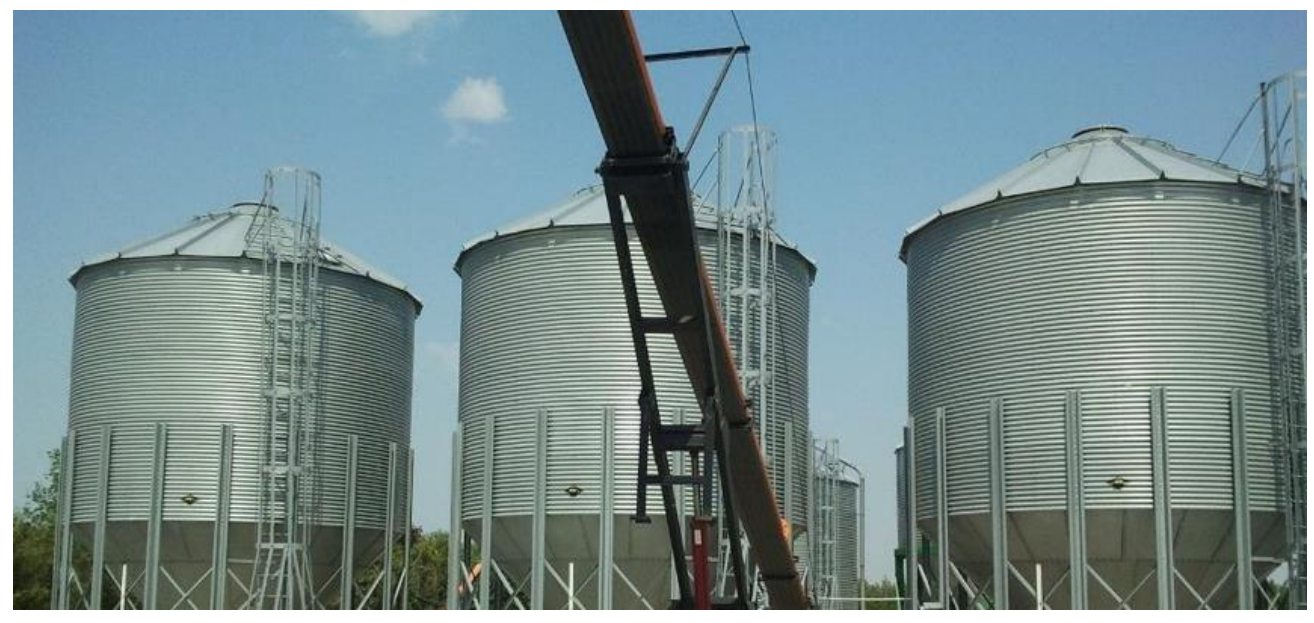

Figure 2: Facility of a farm company 


\section{Deterministic optimization model}

Sets

$J=$ Products $(1 \ldots j \ldots J)$

$S=$ Growers $(1 \ldots s \quad \ldots S)$

$I=$ Possible farm company facilities $(1 \ldots i \ldots I)$

$R=$ Possible distributors locations $(1 \ldots r \ldots R)$

$K=$ Locations of customers $(1 \ldots k \ldots K)$

Parameters

$p_{s j}=$ Cost of purchasing related to product $j$ from grower $s$

$t_{j}=$ selling price $($ product $j)$

$N_{s}=$ fixed-cost associated with grower $s$

$A_{i}=$ fixed-cost related to opening facility $i$ by the farm company

$B_{r}=$ fixed-cost related to selling products via the distributor $r$

$E_{s i}=$ the distance among locations $s$ and $i$ (other distances are defined in the same way)

$F_{j}=$ processing cost of product $j$

$D_{j}=$ transportation expense of product $j$ per km among growers and farm company facilities

$G_{j}=$ transportation expense of product $j$ per $\mathrm{km}$ among farm company facilities and distributors

$H_{j}=$ transportation expense of product $j$ per km among distributors and customers

$d_{k j}=$ demand related to customer (market) $k$ for product $j$

$x_{s j}=$ capacity of grower $s$ for product $j$

$m_{i j}=$ capacity of farm company facility $i$ for product $j$

$o_{r j}=$ capacity of distributor $r$ for product $j$ 
Variables

$P_{s i j}=$ number of product $j$ bought for farm company facility $i$ from grower $s$

$Q_{i r j}=$ number of product $j$ produced by farm company facility $i$ for distributor $r$

$T_{r k j}=$ number of product $j$ sold by distributor $r$ to customer $k$

$W_{s}=1$, if the grower $s$ is selected, 0 , otherwise

$X_{i}=1$, if a farm company facility is located and set up at possible site $i, 0$, otherwise

$Y_{r}=1$, if the distributor which is located in site $r$ is utilized, 0 , otherwise

$$
\begin{aligned}
& \operatorname{Max} z=\sum_{r} \sum_{k} \sum_{j}\left(t_{j}-H_{j} E_{r k}\right) T_{r k j}-\left[\sum_{s} \sum_{i} \sum_{j}\left(p_{s j}+D_{j} E_{s i}\right) P_{s i j}+\sum_{i} \sum_{r} \sum_{j}\left(F_{j}+G_{j} E_{i r}\right) Q_{i r j}\right. \\
& \left.+\sum_{s} N_{s} W_{s}+\sum_{i} A_{i} X_{i}+\sum_{r} B_{r} Y_{r}\right]
\end{aligned}
$$

s.t.

$\sum_{s} P_{s i j}=\sum_{r} Q_{i r j} \quad \forall i, j$

$\sum_{i} Q_{i r j} \geq \sum_{k} T_{r k j} \quad \forall r, j$

$\sum_{r} T_{r k j} \leq d_{k j} \quad \forall k, j$

$\sum_{i} \sum_{j} P_{s i j} \leq W_{s} \sum_{j} x_{s j} \quad \forall s$

$$
\sum_{r} \sum_{j} Q_{i r j} \leq X_{i} \sum_{j} m_{i j} \quad \forall i
$$

$$
\sum_{k} \sum_{j} T_{r k j} \leq Y_{r} \sum_{j} o_{r j} \quad \forall r
$$

$W_{s}, X_{i}, Y_{r} \in\{0,1\} \quad \forall s, i, r$

$$
P_{s i j}, Q_{i r j}, T_{r k j} \geq 0 \quad \forall s, i, j, r, k
$$


The profit of the soybean supply chain is maximized in the objective function of the proposed mathematical formulation. The first part of the objective identifies the profit related to selling soybeans to the customers. The second part is about the transportation and purchasing costs of soybeans from growers to farm company facilities. The next part describes the production and transportation expenses between farm company facilities and distributers. Besides, the fixed-costs related to growers, farm facilities, and distributers are considered in the objective function.

The mathematical model consists of 8 constraints which are mentioned in this paragraph. The connections between the soybeans that are purchased from growers and the soybeans that are delivered to distributors are considered in Constraint (1). Constraint (2) shows that the quantity of products that produced by farm company for distributers is greater than the number of products that are sold to demand markets. Demand is taken into account in Constraint (3). Demand for soybeans must be greater or equal to the quantity of them that are sold. Constraints (4), (5), (6) demonstrate the limitations in capacities of growers, farm facilities, and distributors. Constraints (7) and (8) show 0-1 and non-negative variables.

\section{Application of the model}

The major areas in the Southern and Southwestern of Ontario that are suitable to grow soybeans are shown in Fig. 3. According to this figure, most of the soybeans are obtained in the green areas. One of the concerns of growers is choosing right seed for a specific yield because particular soybeans should be planted on the right farm in order to achieve maximum grains in the following seasons (Marko et al., 2016). 
Soybeans have been grouped by diverse 3-conglycinin subunit compositions and glycinin by Agriculture and Agri-food Canada, Greenhouse \& Processing Crops Research Centre (GPCRC) in Ontario (Bainy, 2007). Major cities which are inside of Ontario are selected as markets. They include Cambridge, Kitchener, Sarnia, Windsor, Woodstock, Stratford, Tilbury, and Waterloo. In addition, three cities in USA are chosen as markets outside of Canada including Cleveland, Detroit, and Marysville. Moreover, there are three potential growers in Blenheim, Binbrook, and Wyoming. In addition, potential farm company facilities are in Kanata and Guelph. Five distributers are located in Chattam, Hensall, Parkhill, Palmerston, and Guelph. The population density is low in Southern and Southwestern of Ontario, and there are significant distances between the cities. Therefore, the transportation cost is high and important in the region. Road is the transportation mode in this study. In this investigation, the distances between the locations (growers, facilities, distributors, and markets) are obtained using Maps in Google. Besides, soybean consumption is calculated in terms of one percent of the population of each market. Other data are provided in Appendix. 


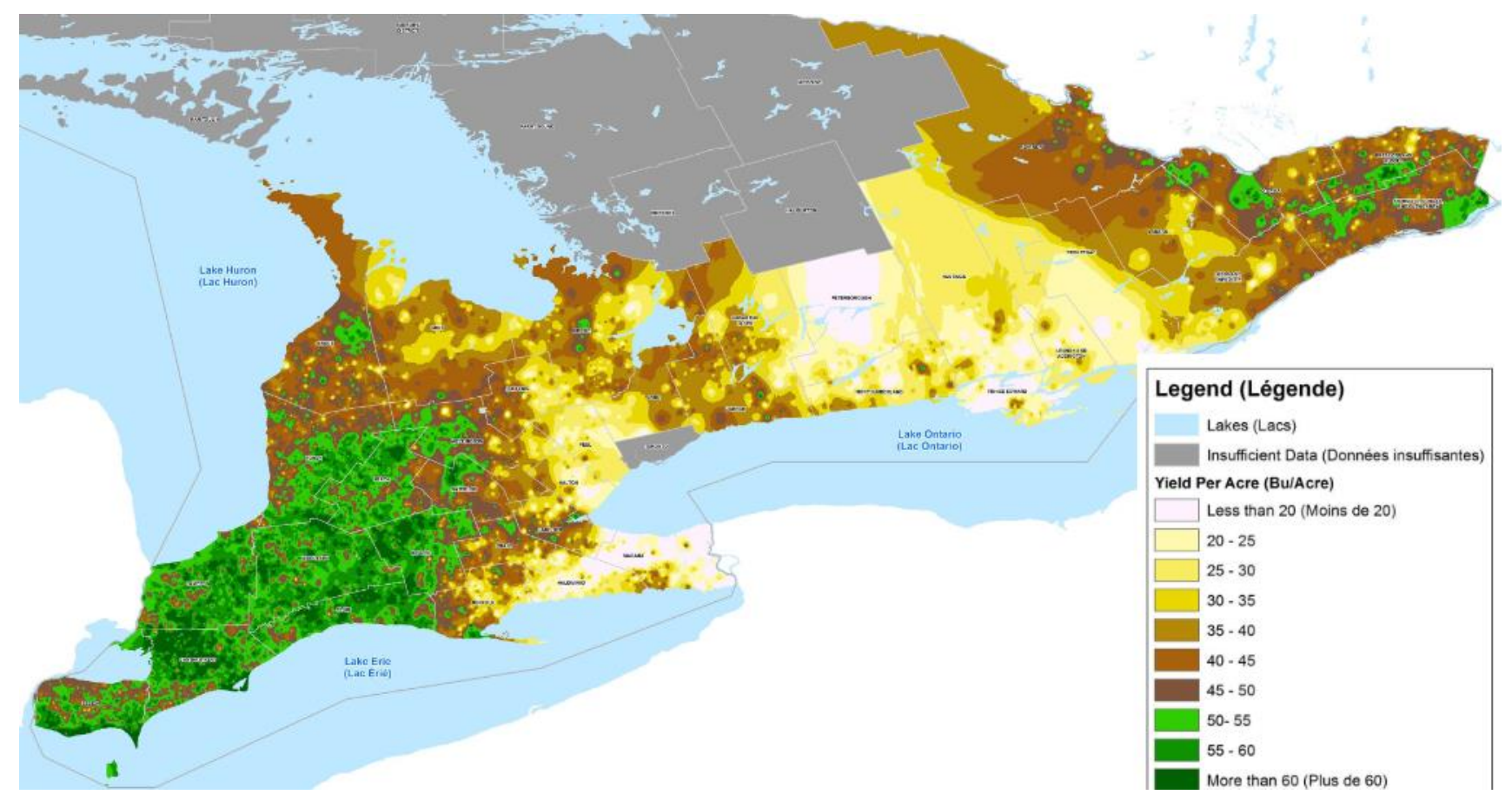

Figure 3: Soybean yields (Map, 2018)

The optimal soybean supply chain network for Products 1 and 2 is shown in Fig. 4. Some symbols are defined to represent growers, farm facilities, distributors, and markets. Growers 1 and 2 (in Blenheim and Binbrook) provide soybean seeds which are sent to Facilities 1 and 2 (in Kanata and Guelph). Soybeans are processed inside of the facilities. Then, they are sent to the distributors. Distributors 1, 2, 3, and 5 (in Chattam, Hensall, Parkhill, and Guelph) send them out to the 11 markets. These markets are the major cities inside and outside of Ontario. The optimal supply chain network is presented in Fig. 4. 


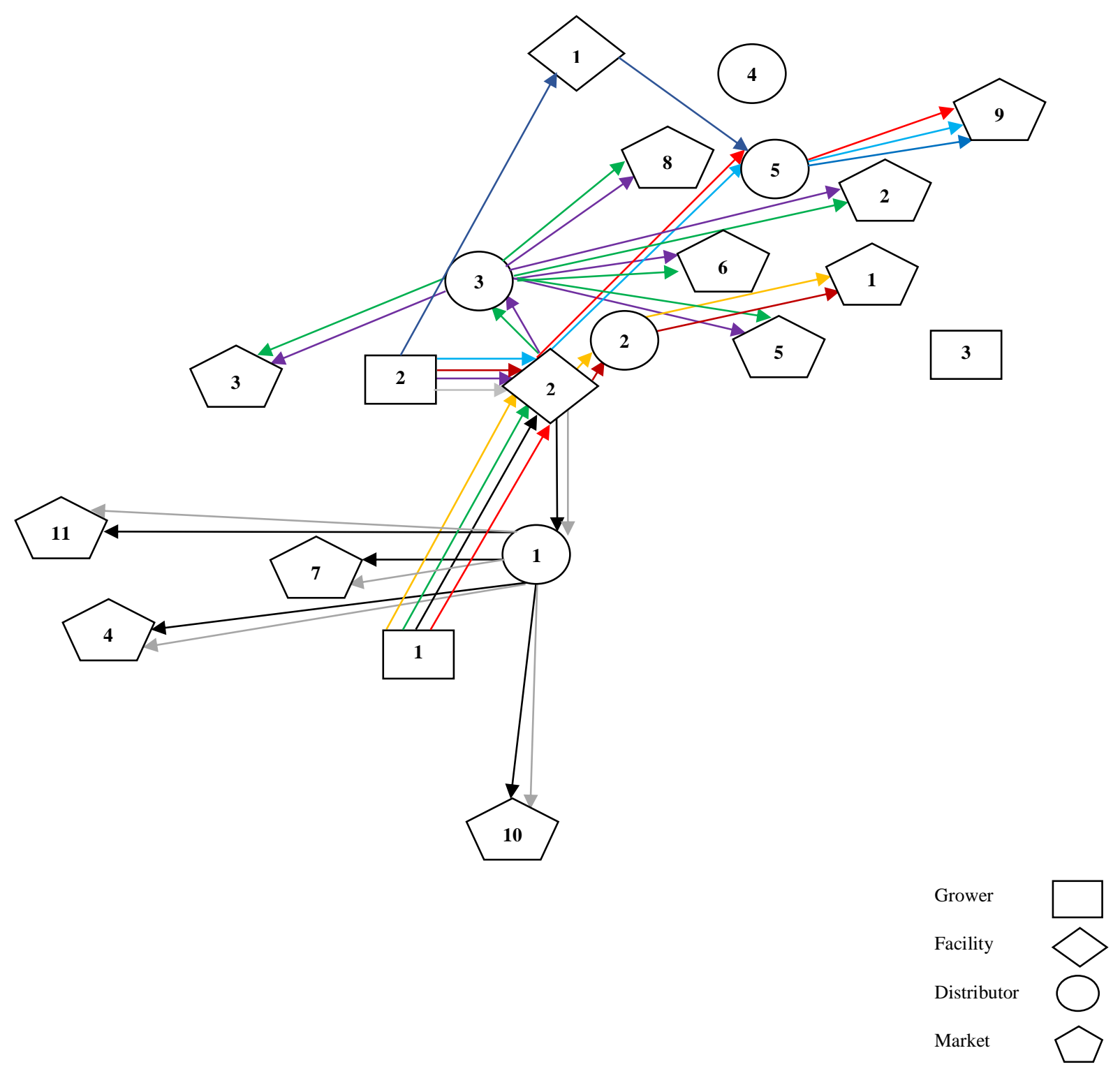

Figure 4: The optimal soybean supply chain network

\section{Extension to multi-period possibilistic model}

One period has been considered in the proposed model. In this section, the model is extended to a multi-period model. $\eta$ is defined as the index of period. In addition, we propose a method to consider uncertainty in the parameters of the optimization model. 
Fuzzy sets theory is utilized to handle imprecise parameters in various fields of operation research (Peidro et al., 2009; Zimmermann, 2012; Sherafati and Bashiri; 2016; Shakourloo et al., 2016; Baykasoğlu and Subulan, 2017; Tosarkani and Amin, 2018a; Naranjo et al., 2018; Majumder and Pratihar, 2018), management science and decision-making processes (Amin and Zhang, 2013; Zadeh et al., 2014; Bhattacharya et al., 2014; Govindan et al., 2015; Tosarkani and Amin, 2018b). In this study, we introduce a possibilistic model to maximize the whole profit of the soybean supply chain network in multiple periods. The objective function and constraints include imprecise parameters. They are written as follows:

$\operatorname{Max} z=\sum_{r} \sum_{k} \sum_{j} \sum_{\eta}\left(\tilde{t}_{j}-\tilde{H}_{j} E_{r k}\right) T_{r k j \eta}-\left(\begin{array}{l}\sum_{s} \sum_{i} \sum_{j} \sum_{\eta}\left(\tilde{p}_{s j}+\tilde{D}_{j} E_{s i}\right) P_{s i j \eta}+\sum_{i} \sum_{r} \sum_{j} \sum_{\eta}\left(\tilde{F}_{j}+\tilde{G}_{j} E_{i r}\right) Q_{i r j \eta} \\ +\sum_{s} \tilde{N}_{s} W_{s}+\sum_{i} \tilde{A}_{i} X_{i}+\sum_{r} \tilde{B}_{r} Y_{r}\end{array}\right)$ s.t.

Constraint (7)

$\sum_{s} P_{s i j \eta}=\sum_{r} Q_{i r j \eta}$ $\forall i, j, \eta$

$\sum_{i} Q_{i r j \eta} \geq \sum_{k} T_{r k j \eta}$ $\forall r, j, \eta$

$\sum_{r} T_{r k j \eta} \tilde{\leq} \tilde{d}_{k j \eta}$

$\forall k, j, \eta$

$\sum_{i} \sum_{j} P_{s i j \eta} \tilde{\leq} W_{s} \sum_{j} \tilde{x}_{s j}$

$\forall s, \eta$

$\sum_{r} \sum_{j} Q_{i r j \eta} \tilde{\leq} X_{i} \sum_{j} \tilde{m}_{i j}$

$\forall i, \eta$

$\sum_{k} \sum_{j} T_{r k j \eta} \tilde{\leq} Y_{r} \sum_{j} \tilde{o}_{r j}$

$\forall r, \eta$

$P_{s i j \eta}, Q_{i r j \eta}, T_{r k j \eta} \geq 0$

$\forall s, i, j, r, k, \eta$ 
A solution approach is developed based on the papers of Cadenas and Verdegay (1997), Peidro et al., (2009), Pishvaei and Khalaf (2016). The new model includes fuzzy coefficients, fuzzy righthand sides, and fuzzy inequality signs. The general form of this type of model is defined by Model (16).

$\operatorname{Max} z=\sum_{f=1}^{n} \tilde{c}_{f} y_{f}$

s.t.

$\sum_{f=1}^{n} \tilde{a}_{e f} y_{f} \tilde{\leq} \tilde{b}_{e}$

$\forall e$

$y_{f} \geq 0$

Where $\tilde{\leq}$ is the fuzzy version of $\leq$ implying that the left-hand side is required to be less than or similar to the right-hand side value (Peidro et al., 2009). According to Cadenas and Verdegay (1997), fuzzy number $\left(\tilde{\gamma}_{e}\right)$ is applied to show the maximum violation of soft constraints. Therefore, Model (17) is the defuzzified version of Model (16).

As illustrated in Fig. 5, $\Lambda_{c f}$ and $\Lambda_{c f}^{\prime}$ represent the lateral margins associated with TFN $\tilde{c}_{f}=\left(u_{f}, c_{f}, w_{f}\right)$.

$\operatorname{Max} z=\sum_{f=1}^{n}\left(\boldsymbol{r}_{f}+\frac{\Lambda_{c_{f}}-\Lambda_{c_{f}}^{\prime}}{3}\right) y_{f}$

s.t.

$\sum_{f=1}^{n}\left(a_{e f}+\frac{\Lambda_{a_{e f}}-\Lambda_{a_{e f}}^{\prime}}{3}\right) y_{f} \leq\left(b_{e}+\frac{\Lambda_{b_{e}}-\Lambda_{b_{e}}^{\prime}}{3}\right)+\left(\gamma_{e}+\frac{\Lambda_{\gamma_{e}}-\Lambda_{\gamma_{e}}^{\prime}}{3}\right)(1-\alpha) \quad \forall e$

$y_{f} \geq 0, \alpha \in[0,1]$ 


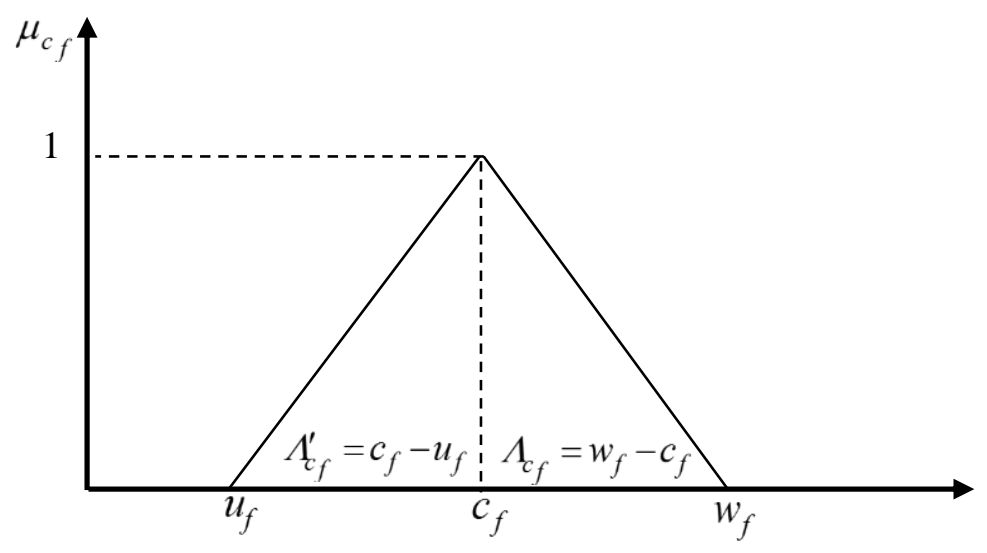

Figure 5: TFN $\tilde{c}_{f}$

Accordingly, the crisp version of the objective function and constraints (11 to 14) are provided as follows:

$$
\begin{aligned}
& \operatorname{Max} z=\sum_{r} \sum_{k} \sum_{j} \sum_{\eta}\left(\left(t_{j}+\frac{\Lambda_{t_{j}}-\Lambda_{t_{j}}^{\prime}}{3}\right)-\left(H_{j}+\frac{\Lambda_{H_{j}}-\Lambda_{H_{j}}^{\prime}}{3}\right) E_{r k}\right) T_{r k j \eta}- \\
& \left(\sum_{s} \sum_{i} \sum_{j} \sum_{\eta}\left(\left(p_{s j}+\frac{\Lambda_{p_{s j}}-\Lambda_{p_{s j}}^{\prime}}{3}\right)+\left(D_{j}+\frac{\Lambda_{D_{j}}-\Lambda_{D_{j}}^{\prime}}{3}\right) E_{s i}\right) P_{s i j \eta}+\sum_{s}\left(N_{s}+\frac{\Lambda_{N_{s}}-\Lambda_{N_{s}}^{\prime}}{3}\right) W_{s}\right. \\
& \left.\sum_{i} \sum_{r} \sum_{j} \sum_{\eta}\left(\left(F_{j}+\frac{\Lambda_{F_{j}}-\Lambda_{F_{j}}^{\prime}}{3}\right)+\left(G_{j}+\frac{\Lambda_{G_{j}}-\Lambda_{G_{j}}^{\prime}}{3}\right) E_{i r}\right) Q_{i r j \eta}+\sum_{i}\left(A_{i}+\frac{\Lambda_{A_{i}}-\Lambda_{A_{i}}^{\prime}}{3}\right) X_{i}+\sum_{r}\left(B_{r}+\frac{\Lambda_{B_{r}}-\Lambda_{B_{r}}^{\prime}}{3}\right) Y_{r}\right)
\end{aligned}
$$

s.t.

Constraints (7), (9), (10), (15)

$$
\begin{array}{ll}
\sum_{r} T_{r k j \eta} \leq\left(d_{k j \eta}+\frac{\Lambda_{d_{k j \eta}}-\Lambda_{d_{k j \eta}}^{\prime}}{3}\right)+\left(\delta_{k j \eta}+\frac{\Lambda_{\delta_{k j \eta}}-\Lambda_{\delta_{k j \eta}}^{\prime}}{3}\right)(1-\alpha) & \forall k, j, \eta \\
\sum_{i} \sum_{j} P_{s i j \eta} \leq W_{s} \sum_{j}\left(x_{s j}+\frac{\Lambda_{x_{s j}}-\Lambda_{x_{s j}}^{\prime}}{3}\right)+\left(\varepsilon_{s j}+\frac{\Lambda_{\varepsilon_{s j}}-\Lambda_{\varepsilon_{s j}^{\prime}}^{\prime}}{3}\right)(1-\alpha) & \forall s, \eta \\
\sum_{r} \sum_{j} Q_{i r j \eta} \leq X_{i} \sum_{j}\left(m_{i j}+\frac{\Lambda_{m_{i j}}-\Lambda_{m_{i j}}^{\prime}}{3}\right)+\left(\theta_{i j}+\frac{\Lambda_{\theta_{i j}}-\Lambda_{\theta_{i j}^{\prime}}^{\prime}}{3}\right)(1-\alpha) & \forall i, \eta
\end{array}
$$




$$
\sum_{k} \sum_{j} T_{r k j \eta} \leq Y_{r} \sum_{j}\left(o_{r j}+\frac{\Lambda_{o_{r j}}-\Lambda_{o_{r j}}^{\prime}}{3}\right)+\left(v_{r j}+\frac{\Lambda_{v_{r j}}-\Lambda_{v_{r j}}^{\prime}}{3}\right)(1-\alpha) \quad \forall r, \eta
$$

In this study, we estimate the lower and upper values of each TFN as 10 percent decrease and increase of its nominal value. Furthermore, $\delta_{k j \eta}, \varepsilon_{s j}, \theta_{i j}$, and $v_{r j}$ are computed as 25 percent of $d_{k j \eta}, x_{s j}, m_{i j}$, and $o_{r j}$, respectively. As mentioned previously, $\alpha \in[0,1]$, and various objective's values can be calculated based on different levels of $\alpha$-cut. On this matter, decision-makers play a prominent role to decide about appropriate pair of $(\alpha, z)$. Table 2 includes the optimal solutions of the multi-period possibilistic model for the soybean supply chain network.

Table 2: The optimal solutions based on different satisfaction levels

\begin{tabular}{lll}
\hline$\alpha$ & Total profit & Selected entities \\
\hline 0 & $11,760,557.68$ & $W_{1}, W_{2}-X_{1}, X_{2}-Y_{1}, Y_{3}, Y_{5}$ \\
0.1 & $11,524,960.44$ & $W_{1}, W_{2}-X_{1}, X_{2}-Y_{1}, Y_{3}, Y_{5}$ \\
0.2 & $11,289,363.21$ & $W_{1}, W_{2}-X_{1}, X_{2}-Y_{1}, Y_{3}, Y_{5}$ \\
0.3 & $11,053,765.98$ & $W_{1}, W_{2}-X_{1}, X_{2}-Y_{1}, Y_{3}, Y_{5}$ \\
0.4 & $10,817,748.74$ & $W_{1}, W_{2}-X_{1}, X_{2}-Y_{1}, Y_{2}, Y_{3}, Y_{5}$ \\
0.5 & $10,582,151.51$ & $W_{1}, W_{2}-X_{1}, X_{2}-Y_{1}, Y_{2}, Y_{3}, Y_{5}$ \\
0.6 & $10,346,554.27$ & $W_{1}, W_{2}-X_{1}, X_{2}-Y_{1}, Y_{2}, Y_{3}, Y_{5}$ \\
0.7 & $10,110,957.04$ & $W_{1}, W_{2}-X_{1}, X_{2}-Y_{1}, Y_{2}, Y_{3}, Y_{5}$ \\
0.8 & $9,875,359.81$ & $W_{1}, W_{2}-X_{1}, X_{2}-Y_{1}, Y_{2}, Y_{3}, Y_{5}$ \\
0.9 & $9,639,762.58$ & $W_{1}, W_{2}-X_{1}, X_{2}-Y_{1}, Y_{2}, Y_{3}, Y_{5}$ \\
1 & $9,404,165.33$ & $W_{1}, W_{2}-X_{1}, X_{2}-Y_{1}, Y_{2}, Y_{3}, Y_{5}$ \\
\hline
\end{tabular}


To assign the satisfaction level, type of uncertain parameters should be taken into account (Pishvaei and Khalaf, 2016). Hence, it is aimed to investigate whether entities are able to fulfill unpredictable market demand. On this matter, capability of increase in capacity by growers, facilities, and distributers should be examined by decision-makers. As illustrated in Table 2, changing the satisfaction level has the reverse impact on the total profit. In other words, as $\alpha$ increases, $z$ decreases (toward the deterministic value), since the uncertain parameters are less allowed to deviate. In this study, as $\alpha$ decreases from 0.4 to 0.3 , number of distributers required to be opened decreases as well. This process happens because of the increase in the capacity.

\section{Conclusions}

Managing food supply chains is a challenging task that involves many elements. In this research, we have focused on supply chain management of soybean. The network includes growers, farm facilities, distributors, and finally customers (demand markets). To our knowledge, soybean supply chain network design and configuration have been ignored in academic literature. Therefore, this research is novel among food supply chain publications.

We have proposed a mixed-integer linear programming formulation to configure the soybean logistics network. Multiple elements such as growers, locations of facilities, distributors, and markets (customers) have been considered in this paper. Furthermore, multiple products (different types of soybeans) have been taken into account. We have investigated the application of the proposed model in a soybean supply chain network in Ontario. There are several soybean companies and growers in this region. The results of the optimization formulation have been illustrated using maps. 
Some parameters are not deterministic in reality (e.g., demand). The proposed mathematical model has been extended using possibilistic approach to deal with uncertain factors of the mathematical model. To our knowledge, uncertain factors have been ignored in most of the food logistics networks papers. Based on our analyses, the proposed possibilistic model is an effective approach to manage uncertainty in the soybean supply chain problem. This method also can be applied in other problems in logistics management area.

This research can be extended in different directions. We focused on soybean supply chain network in this paper. It is valuable to investigate supply chains of other types of foods such as meat, and compare the results. The other future avenue is considering uncertainty in the parameters of the optimization model by other techniques such as decision trees, and analyze the results. Another future investigation is developing a multiple objectives mathematical model based on our proposed model.

\section{Acknowledgements}

This study has been supported by NSERC Discovery grant. 


\section{Appendix}

Table 3: The values of some parameters in the deterministic model

$$
\begin{array}{ll}
N_{s}=932(s=1,2,3) & F_{j}=15(j=1,2) \\
A_{i}=8,090(i=1,2) & G_{j}=0.005(j=1,2) \\
B_{r}=420(r=1,2,3,4,5) & H_{j}=0.005(j=1,2) \\
t_{j}=502(j=1,2) & x_{s j}=10,000(s=1,2,3 ; j=1,2) \\
D_{j}=0.005(j=1,2) & m_{i j}=15,000(i=1,2 ; j=1,2) \\
O_{r j}=10,000(r=1,2,3,4,5 ; j=1,2) &
\end{array}
$$

Table 4: Purchasing cost related to product $j$ from grower $s$

\begin{tabular}{lll}
\hline$p_{s j}$ & 1 & 2 \\
\hline 1 & 300 & 300 \\
2 & 200 & 200 \\
3 & 500 & 500 \\
\hline
\end{tabular}


Table 5: Demand related to customer (market) $k$ for product $j$

\begin{tabular}{lll}
\hline$d_{k j}$ & 1 & 2 \\
\hline 1 & $1,342.8$ & $1,342.8$ \\
2 & $2,046.6$ & $2,046.6$ \\
3 & 57.3 & 57.3 \\
4 & $2,182.7$ & $2,182.7$ \\
5 & 409.02 & 409.02 \\
6 & 314.65 & 314.65 \\
7 & 300 & 300 \\
8 & 987.80 & 987.80 \\
9 & 5,510 & 5,510 \\
10 & 385.8 & 385.8 \\
11 & $6,727.9$ & $6,727.9$ \\
\hline
\end{tabular}




\section{References}

Ahumada, O., Villalobos, J. R., \& Mason, A. N. (2012). Tactical planning of the production and distribution of fresh agricultural products under uncertainty. Agricultural Systems, 112, 1726.

Amin, S. H., \& Zhang, G. (2013). A three-stage model for closed-loop supply chain configuration under uncertainty. International Journal of Production Research, 51(5), 1405-1425.

Amorim, P., Curcio, E., Almada-Lobo, B., Barbosa-Póvoa, A. P., \& Grossmann, I. E. (2016). Supplier selection in the processed food industry under uncertainty. European Journal of Operational Research, 252(3), 801-814.

Aras, N., \& Bilge, Ü. (2018). Robust supply chain network design with multi-products for a company in the food sector. Applied Mathematical Modelling, 60, 526-539.

Asche, F., Cojocaru, A. L., \& Roth, B. (2018). The development of large scale aquaculture production: A comparison of the supply chains for chicken and salmon. Aquaculture, 493, 446-455.

Baghalian, A., Rezapour, S., \& Farahani, R. Z. (2013). Robust supply chain network design with service level against disruptions and demand uncertainties: A real-life case. European Journal of Operational Research, 227(1), 199-215.

Bainy, E. M. Selection of Ontario Soybean Varieties Tailored for Specific Food Processing Functionality. ProQuest, 2007.

Banasik, A., Kanellopoulos, A., Claassen, G. D. H., Bloemhof-Ruwaard, J. M., \& van der Vorst, J. G. (2017). Assessing alternative production options for eco-efficient food supply chains using multi-objective optimization. Annals of Operations Research, 250(2), 341-362. 
Baykasoğlu, A., \& Subulan, K. (2017). Constrained fuzzy arithmetic approach to fuzzy transportation problems with fuzzy decision variables. Expert Systems with Applications, 81, 193-222.

Bhattacharya, A., Mohapatra, P., Kumar, V., Dey, P. K., Brady, M., Tiwari, M. K., \& Nudurupati, S. S. (2014). Green supply chain performance measurement using fuzzy ANP-based balanced scorecard: a collaborative decision-making approach. Production Planning \& Control, 25(8), 698-714.

Cui, Y. Y., Guan, Z., Saif, U., Zhang, L., Zhang, F., \& Mirza, J. (2017). Close loop supply chain network problem with uncertainty in demand and returned products: Genetic artificial bee colony algorithm approach. Journal of cleaner production, 162, 717-742.

De Laporte, A. V., Weersink, A. J., \& McKenney, D. W. (2016). Effects of supply chain structure and biomass prices on bioenergy feedstock supply. Applied energy, 183, 1053-1064.

Garrett, R. D., Lambin, E. F., \& Naylor, R. L. (2013). Land institutions and supply chain configurations as determinants of soybean planted area and yields in Brazil. Land Use Policy, 31, 385-396.

Ghelichi, Z., Saidi-Mehrabad, M., \& Pishvaee, M. S. (2018). A stochastic programming approach toward optimal design and planning of an integrated green biodiesel supply chain network under uncertainty: A case study. Energy, 156, 661-687.

Gollnow, F., Hissa, L. D. B. V., Rufin, P., \& Lakes, T. (2018). Property-level direct and indirect deforestation for soybean production in the Amazon region of Mato Grosso, Brazil. Land Use Policy, 78, 377-385.

Govindan, K., Jafarian, A., \& Nourbakhsh, V. (2015). Bi-objective integrating sustainable order allocation and sustainable supply chain network strategic design with stochastic demand using 
a novel robust hybrid multi-objective metaheuristic. Computers \& Operations Research, 62, 112-130.

Govindan, K. (2018). Sustainable consumption and production in the food supply chain: A conceptual framework. International Journal of Production Economics, 195, 419-431.

Gupta, A., \& Maranas, C. D. (2003). Managing demand uncertainty in supply chain planning. Computers \& chemical engineering, 27(8-9), 1219-1227.

HASUIKE, T., KASHIMA, T., \& MATSUMOTO, S. (2014). Data-driven Food Supply Chain Optimization under Uncertain Crop Productions and Consumers' Demands. Innovation and Supply Chain Management, 8(4), 150-156.

HiCoat. (2018). http://soycanada.ca/industry/soybean-processing/, accessed June 12018.

Majumder, S., \& Pratihar, D. K. (2018). Multi-sensors data fusion through fuzzy clustering and predictive tools. Expert Systems with Applications, 107, 165-172.

Map. (2018). http://www.agricorp.com/SiteCollectionDocuments/PI-soybeans-YieldMap-2016enfr.pdf, accessed August 12018.

Marko, O., Brdar, S., Panic, M., Lugonja, P., \& Crnojevic, V. (2016). Soybean varieties portfolio optimisation based on yield prediction. Computers and Electronics in Agriculture, 127, 467474.

Mishra, A., Buchanan, R. L., Schaffner, D. W., \& Pradhan, A. K. (2016). Cost, quality, and safety: A nonlinear programming approach to optimize the temperature during supply chain of leafy greens. LWT-Food Science and Technology, 73, 412-418.

Mirzapour Al-E-Hashem, S. M. J., Malekly, H., \& Aryanezhad, M. B. (2011). A multi-objective robust optimization model for multi-product multi-site aggregate production planning in a 
supply chain under uncertainty. International Journal of Production Economics, 134(1), 2842.

Mogale, D. G., Kumar, M., Kumar, S. K., \& Tiwari, M. K. (2018). Grain silo location-allocation problem with dwell time for optimization of food grain supply chain network. Transportation Research Part E: Logistics and Transportation Review, 111, 40-69.

Mohammed, A., \& Wang, Q. (2017a). Multi-criteria optimization for a cost-effective design of an RFID-based meat supply chain. British Food Journal, 119(3), 676-689.

Mohammed, A., \& Wang, Q. (2017b). Developing a meat supply chain network design using a multi-objective possibilistic programming approach. British Food Journal, 119(3), 690-706.

Mohammed, A., \& Wang, Q. (2017c). The fuzzy multi-objective distribution planner for a green meat supply chain. International Journal of Production Economics, 184, 47-58.

Naranjo, R., Arroyo, J., \& Santos, M. (2018). Fuzzy modeling of stock trading with fuzzy candlesticks. Expert Systems with Applications, 93, 15-27.

Peidro, D., Mula, J., Poler, R., \& Verdegay, J. L. (2009). Fuzzy optimization for supply chain planning under supply, demand and process uncertainties. Fuzzy sets and systems, 160(18), 2640-2657.

Pishvaee, M. S., \& Khalaf, M. F. (2016). Novel robust fuzzy mathematical programming methods. Applied Mathematical Modelling, 40(1), 407-418.

Rahimi, E., Paydar, M. M., Mahdavi, I., Jouzdani, J., \& Arabsheybani, A. (2018). A robust optimization model for multi-objective multi-period supply chain planning under uncertainty considering quantity discounts. Journal of Industrial and Production Engineering, 35(4), 214228. 
Reis, S. A., \& Leal, J. E. (2015). A deterministic mathematical model to support temporal and spatial decisions of the soybean supply chain. Journal of transport geography, 43, 48-58.

Riaz, M. N. (2006). Soy Applications in Food. Boca Raton, FL: CRC Press. ISBN 0-8493-29817.

Rijpkema, W. A., Hendrix, E. M., Rossi, R., \& van der Vorst, J. G. (2016). Application of stochastic programming to reduce uncertainty in quality-based supply planning of slaughterhouses. Annals of Operations Research, 239(2), 613-624.

Rong, A., Akkerman, R., \& Grunow, M. (2011). An optimization approach for managing fresh food quality throughout the supply chain. International Journal of Production Economics, 131(1), 421-429.

Sel, Ç., Soysal, M., \& Çimen, M. (2017). A green model for the catering industry under demand uncertainty. Journal of Cleaner Production, 167, 459-472.

Shakourloo, A., Kazemi, A., Javad, M. O. M. (2016). A new model for more effective supplier selection and remanufacturing process in a closed-loop supply chain. Applied Mathematical Modelling, 40(23), 9914-9931.

Sherafati, M., \& Bashiri, M. (2016). Closed loop supply chain network design with fuzzy tactical decisions. Journal of Industrial Engineering International, 12(3), 255-269.

Simangunsong, E., Hendry, L. C., \& Stevenson, M. (2012). Supply-chain uncertainty: a review and theoretical foundation for future research. International Journal of Production Research, 50(16), 4493-4523.

Soybean. (2018). https://soycanada.ca/industry/industry-overview/, accessed July 12018. 
Soysal, M., Bloemhof-Ruwaard, J. M., \& Van der Vorst, J. G. A. J. (2014). Modelling food logistics networks with emission considerations: The case of an international beef supply chain. International Journal of Production Economics, 152, 57-70.

Soysal, M., Bloemhof-Ruwaard, J. M., Haijema, R., \& van der Vorst, J. G. (2015). Modeling an Inventory Routing Problem for perishable products with environmental considerations and demand uncertainty. International Journal of Production Economics, 164, 118-133.

Tosarkani, B. M., \& Amin, S. H. (2018a). A possibilistic solution to configure a battery closedloop supply chain: Multi-objective approach. Expert Systems with Applications, 92, 12-26.

Tosarkani, B.M., \& Amin, S.H. (2018b). A multi-objective model to configure an electronic reverse logistics network and third party selection. Journal of Cleaner Production, 198, 662682.

Wu, X., Nie, L., Xu, M., \& Yan, F. (2018). A perishable food supply chain problem considering demand uncertainty and time deadline constraints: Modeling and application to a high-speed railway catering service. Transportation Research Part E: Logistics and Transportation Review, 111, 186-209.

Zadeh, L. A., Fu, K. S., \& Tanaka, K. (Eds.). (2014). Fuzzy sets and their applications to cognitive and decision processes: Proceedings of the us-japan seminar on fuzzy sets and their applications, held at the university of california, berkeley, california, july 1-4, 1974. Academic press.

Zimmermann, H. J. (2012). Fuzzy sets, decision making, and expert systems (Vol. 10). Springer Science \& Business Media. 
Zheng, Z., \& Cao, M. (2011). Research on supply chain optimization of foreign food company C. In Management Science and Industrial Engineering (MSIE), 2011 International Conference on (pp. 940-943). IEEE.

Zortea, R. B., Maciel, V. G., \& Passuello, A. (2018). Sustainability assessment of soybean production in Southern Brazil: A life cycle approach. Sustainable Production and Consumption, 13, 102-112. 